\title{
Business Ethics
}

A EUROPEAN REVIEW

\section{Greening the Hospitality Industry in the Developing World: Analysis of the Drivers and Barriers}

\begin{tabular}{|c|c|}
\hline Journal: & Business Ethics: A European Review \\
\hline Manuscript ID & BEER-2016-Dec-0272.R6 \\
\hline Wiley - Manuscript type: & Original Article \\
\hline Keywords: & $\begin{array}{l}\text { Qualitative Analysis < Methods, Corporate Philanthropy < Business- } \\
\text { Society Terms, Ethics, Institutional Theory < Theory, Developing } \\
\text { Countries < Context?, Ecological/Sustainability < Change Level }\end{array}$ \\
\hline Areas of Expertise: & Sustainability, Business Ethics, Hospitality \\
\hline Abstract: & $\begin{array}{l}\text { The implementation of sustainability agendas in the tourism and } \\
\text { hospitality industry in developing countries has received little scholarly } \\
\text { attention. Working to fill this gap, this paper provides a holistic analysis } \\
\text { of the drivers of and barriers to sustainability initiatives in the Malawian } \\
\text { hospitality industry. Drawing insights from the resource based view and } \\
\text { institutional theory, it highlights that tensions between global and local } \\
\text { norms and values are as important as tensions between internal } \\
\text { organizational factors and the isomorphic forces within the organizational } \\
\text { fields for implementing sustainability agendas. The paper further reveals } \\
\text { the mediating role played by firm size and ownership. It thus makes a } \\
\text { contribution to understanding of the role of business in society by } \\
\text { focusing on the complex dynamics of adoption of sustainability agendas } \\
\text { in an under-researched context, and demonstrating how tensions } \\
\text { between internal organizational factors and local societal expectations } \\
\text { within the host countries can shape the nature and focus of the } \\
\text { sustainability agenda itself. }\end{array}$ \\
\hline
\end{tabular}

\section{SCHOLARONE Manuscripts}



Drivers and Barriers

\begin{abstract}
The implementation of sustainability agendas in the tourism and hospitality industry in developing countries has received little scholarly attention. Working to fill this gap, this paper provides a holistic analysis of the drivers of, and barriers to, sustainability initiatives in the Malawian hospitality industry. Drawing insights from the resource based view and institutional theory, it highlights that tensions between global and local norms and values are as important as tensions between internal organisational factors and the isomorphic forces within the organisational fields for implementing sustainability agendas. The paper further reveals the mediating role played by firm size and ownership. It, thus, makes a contribution to the understanding of the role of business in society by focusing on the complex dynamics associated with the adoption of sustainability agendas in an under-researched context, and demonstrating how tensions between internal organisational factors and local societal expectations within the host countries can shape the nature and focus of the sustainability agenda itself.
\end{abstract}

\subsection{INTRODUCTION}

There is an established body of literature that investigates the fundamental questions about why some firms in the tourism and hospitality industries adopt a sustainability agenda, whereas other firms do not adopt a sustainability agenda (Ayuso 2006; Best \& Thapa 2013; Dodds \& Holmes 2011; Graci \& Dodds 2008; Mensah 2006; Tang, Amran \& Goh 2014; Tzschenke, Kirk \& Lynch 2004). However, most studies cover small, medium and large hotels based in the developed and western world (Ayuso 2006; Dodds \& Holmes 2011; Graci \& Dodds 2008; Tzschenke Kirk \& Lynch 2004). At the same time, we still know little about the drivers of and barriers to sustainability in the tourism and hospitality industry in developing countries (Best \& Thapa 2013; Mensah 2006; Tang et al. 2014). The drivers of social and environmental responsibilities in developing countries have been shown to be very distinct from these drivers in developed countries because of colonial legacies, different levels of economic development or different religious influences (Jamali \& Karam 2018; Perry \& Ahmad 2016; Sahasranamam \& Ball 2018). Therefore, it would 

institutional contexts (Best \& Thapa 2013; Jamali \& Karam 2018). Likewise, it has been shown that internal organizational characteristics play a crucial role in the sustainability agendas of developing countries (Tang et al. 2014). It is therefore fundamental to address the complementarity of and frictions between internal organizational characteristics and external factors in influencing firms' commitment to sustainability agendas in the tourism and hospitality industries, particularly in relatively under-researched regions.

This paper makes four important contributions to the literature and practice. The first contribution is a response to the calls for more empirical studies that combine both an internal and external perspective in investigating social and environmental corporate agendas (Frynas \&Yamahaki 2016; Mallahi, Frynas, Sun $\&$ Siegel, 2016). The theoretical focus in the corporate social responsibility (CSR) research tends to be on its external drivers (Fryanas \&Yamahaki, 2016, p. 269), but our approach supports Mallahi, Frynas, Sun \& Siegel (2016) who call for more studies that focus on sustainability or CSR drivers to be grounded in combining the theories associated with external drivers with the theories associated with internal drivers. We therefore propose a theoretical framework (Figure 1) that integrates internal organizational factors and isomorphic factors in the organizational field (Frynas \& Yamahaki 2016; Mallahi et al. 2016) and the nature of the firm, one of the key elements of National Business Systems (NBS). The integration of theories allows for a 'more robust and richer empirical testing' (Frynas \& Yamahaki, 2016, p. 269). The second contribution that proceeds from the premise of our first contribution is to extend our understanding of the role of business in society by focusing on the complex dynamics of the adoption of sustainability agendas in an underresearched context and by demonstrating how the tensions between internal organizational factors and local societal expectations within their host countries can shape the nature and focus of the sustainability agenda itself. Third, by considering the combined influence of internal organizational and institutional factors in the adoption of sustainability agendas in Malawi, this paper responds to recent calls for future research to consider both the internal and external drivers of and barriers to the implementation of sustainability practices within and that relate to the hospitality industry in the developing country context (Best \& Thapa 2013; Melissen et al. 2018). The final contribution is practical in nature. This research clearly suggests the 
1 need to strengthen the interaction between local institutional factors (for example, local societal

2 expectations, regulations and the civil society or non-governmental organizations including trade unions

3 and professional bodies) and the internal organizational factors to develop substantive sustainability

4 agendas.

5

$6 \quad 2.0 \quad$ THEORETICAL PERSPECTIVES

7 The extant literature reveals a number of factors that drive and constrain the adoption of sustainability

8 initiatives by firms. These factors typically exist either as internal organizational attributes or external

9 influences that originate from the institutional environments of firms.

\section{$11 \quad 2.1 \quad$ Internal Organizational Factors}

12 The extant literature in the field of hospitality and tourism shows that there is a gap in the empirical studies

13 that investigate the internal drivers of and barriers to the sustainability agenda, and this gap is even more

14 pronounced for the developing country context (Tang et al. 2014). Insights from Russo \& Fouts' (1997)

15 resource based view have often been used. In line with the resource-based perspective, empirical studies

16 suggest that the extent to which firms possess these resources determines whether a firm will or will not

17 adopt a sustainability agenda (Ayuso 2006; Chan 2008; Graci \& Dodds 2008; Tzschenke et al. 2004). These

18 resources can help provide a firm with the capacity to absorb the cost of undertaking sustainable practices.

19 Essentially, the firms that have sufficient financial resources are more likely to take some risks and invest

20 in the development of innovations and technological advances than the firms that face financial resource constraints (Best \& Thapa 2013; Chan 2008; Dodds \& Holmes 2011).

Another issue related to resource endowment is firm size. Prior studies show that large firms are 23 more likely to have slack resources, which can allow them to adopt sustainable business practices. In 24 contrast, small firms that often have limited resources are less likely to engage in sustainability initiatives 
1 (Benito-Hernández, Platero-Jaime, \& Esteban-Sánchez 2016). In fact, Best \& Thapa (2013) show that a

2 lack of time to search for and learn about new ideas may have hindered the adoption of certain aspects of

3 sustainability by small firms. Other scholars suggest that the availability of knowledge and information

4 about certain aspects of sustainability can also deter the uptake of sustainability initiatives (Dodds \&

5 Holmes 2011; Revell \& Blackburn 2007). Furthermore, a lack of knowledge about the business case for

6 sustainable practices can discourage firms from embarking on sustainability initiatives (Ayuso 2006; Graci

$7 \quad \&$ Dodds 2008).

Organizational values and the personal values of managers and owners - which the resource-based

9 view considers to be intangible resources - play a fundamental role in the adoption of sustainability agendas

10 by firms (Aragón Amonarriz \& Iturrioz Landart 2016; Eweje 2011; Tang et al. 2014; Tinnish \& Lynch

11 2016; Tzschenke et al. 2004). The personal values of owners and top managers can be significant not only

12 during the allocation of resources (Eweje 2011; Tang et al. 2014; Tinnish \& Lynch 2016; Tzschenke et al.

13 2004) but also during a firm's interface with external institutional pressures (Jain \& Jamali 2016). Personal

14 values may, in turn, determine the dominant organizational values and cultures and overall orientation to

15 sustainability (Lehnert, Craft, Singh \& Park 2016; Rua, Lawter \& Andreassi 2017). Williams, Schaefer \&

16 Blundel (2017) argue that some owner/managers who are mainly concerned with sustainability issues to

17 achieve status and authority and to increase firm value are largely guided by the enlightened self-interest

18 values. In contrast, owner/managers who place considerable value on social justice and selflessness tend to 19 be guided by universalism and benevolent values.

\section{$\begin{array}{lll}21 & \mathbf{2 . 2} & \text { Institutional Factors }\end{array}$}

22 Institutional theory is widely adopted by scholars to understand the organizational responses towards 23 external environmental stimuli (DiMaggio \& Powell 1983; Frynas et al. 2016; Pérez-López, Moreno24 Romero \& Barkemeyer, 2015; Viveros 2016). Below, we review the two fundamental institutional logics - 
organizational fields ${ }^{1}$ (DiMaggio \& Powell 1983; Meyer \& Rowan 1977; Scott 2008) and NBS (Jamali \&

2 Neville 2011; Kostova \& Roth 2002; Matten \& Moon 2008; Whitley 1999) - which explain the adoption 3 of a sustainability agenda.

\section{$5 \quad$ 2.2.1 Coercive, mimetic and normative forces in the organizational field}

6 Institutional theorists argue that organizations are subjected to coercive, normative and mimetic forces to 7 conform to the demands of their environment (DiMaggio \& Powell 2003; Scott 2008). First, coercive forces may emanate from regulatory and non-regulatory bodies and consumers, which often pressure organizations to pursue actions that are in conformity with certain sustainability standards (Kostova \& Roth 2002; Soobaroyen \& Ntim 2013). Pressure can come from sustainability-oriented regulations and industry associations' codes. (Ayuso 2006; Rivera 2004). Other studies have suggested that customers with a strong

12 sustainability value can demand the increased integration of sustainability issues into firms' operations

13 (Ayuso 2006; Best \& Thapa 2013). Second, organizations can also adopt certain practices through mimetic 14 mechanisms (Meyer \& Rowan 1977; Scott 2008). Firms tend to copy the best practices of their peers and 15 the practices that are considered to be successful within their industry (Rivera 2004) to remain competitive.

16 This is especially relevant in the contexts where customers reward socially oriented firms (Graafland \& 17 Smid 2015). Finally, normative pressures often originate from the accepted norms and values that guide 18 behaviour and conduct within the context of membership in professional networks. Evidence suggests that 19 these sustainability values are increasingly becoming integral to the norms and values of some professional 20 networks. These norms, when translated into organizational practices, may be reinforced through the 21 network's educational and advocacy programmes and rewards systems. For most of the developing country 22 context, these professional associations, as highlighted by Tang et al. (2014), may be ineffective and

\footnotetext{
${ }^{1}$ An organizational field is regarded as a domain where different organizations interact with one another. Through the various isomorphic forces, these interactions often lead to desired changes in the behavior of the targeted organizations.
} 
1 symptomatic of a lack of pressure from the general public on these associations to embrace sustainable

2 business practices (Ali, Frynas \& Mahmood 2017).

\subsubsection{National Business Systems}

5 Scholars are increasingly using the NBS approach to understand the cross-national variations in firms'

6 behaviour in response to social issues (Forcadell and Aracil 2017; Hofman, Moon \& Wu 2017; Jamali \&

7 Neville 2011; Kostova \& Roth 2002; Matten \& Moon 2008; Sahasranamam \& Ball 2018; Whitley 1999).

8 The NBS approach posits that a given country's combinations of political, financial, educational and labour

9 systems, as well as its cultural systems, can affect the behaviours of firms. In addition to these four key

10 elements, scholars such as Matten \& Moon (2008) and Hofman et al. (2017) consider the features of NBS

11 such as the nature of the firm and market coordination processes to be fundamental to the nature of the CSR

12 (sustainability) that can be pursued. In fact, unlike many previous empirical studies that focus on the four

13 primary systems, Hofman et al. (2017) suggest that the nature of firms expressed in terms of ownership and

14 size can determine the adoption of CSR (sustainability) agendas in a given context. They found that in

15 China, two forms of CSR existed. One CSR agenda is implemented by state-owned large enterprises that

16 aligns with the duality of the demands from the local society and the global arena, and another agenda is

17 favoured by family-owned SMEs and is often aimed at responding to local expectations and building a

18 positive image within the local communities. The findings of this study are consistent with Samara et al.

19 (2018) and Charbel et al. (2013) who found that family-owned businesses are more likely to have a strong

20 attachment to their local communities, but these scholars extend their findings by suggesting that the nature

21 of governance structures can either enhance or inhibit firms' ability to adopt a broad-based sustainability

22 agenda. Similarly, it is suggested that the nature of the NBS in the country in which it operates can

23 determine whether a firm displays the explicit or implicit form of CSR (see also Hyatt \& Berente 2017;

24 Jamali and Neville 2011). Other studies, however, raise some doubts about the relevance of the NBS 
1 framework in its current form in contexts other than developed and western countries (Amaeshi et al. 2016a

2 \& b; Forcadell and Aracil 2017; Hofman et al. 2017; Jamali and Karam, 2018; Jamali \& Neville 2011;

3 Muthuri and Gilbert 2011; Wood and Frynas 2006).

\section{Insert Figure 1 here}

\section{$6 \quad$ 3.0 Methods}

7 Our study adopted a qualitative research approach because this approach provided us with an opportunity 8 to gain a broader understanding not only of the drivers of sustainability but also, more importantly, of the 9 specific barriers that hospitality firms face in the adoption of sustainability in a developing country such as 10 Malawi. We employed purposive sampling in which respondents were selected based on their role in the 11 adoption and implementation of the sustainability agenda within their firms. As such, we identified the 12 participants who we thought could be relevant to our study by using our contacts from the government's 13 ministries of Trade and Industry and Tourism and Culture. To identify the specific drivers and barriers 14 relevant to firms in the Malawian hospitality industry, we interviewed not only the managers and owners 15 of firms who are actively pursuing sustainability agendas but also the managers and owners who do not 16 pursue any sustainability agenda. Through a snow-balling approach, we asked the first few respondents to 17 recommend to us some owners and managers of firms who are not only involved in sustainability but also 18 the owners and managers who are not undertaking any sustainability initiatives. The details of the 19 interviewees from the participating firms are presented in Table 1.

We conducted 25 semi-structured interviews between July 2015 and July 2016. These interviews

21 involved the owners and managers of SMEs and large firms and a limited number of other stakeholders $(n$

$22=4$ ) to further explore the specific drivers and barriers. Semi-structured interviews (SSI) were deemed to 23 be appropriate for this study because of their in-built flexibility that allows respondents to freely articulate 
1 their views and lived experiences regarding a particular phenomenon. The duration of the interviews ranged

2 between 30 and 70 minutes. The actual duration was often arrived at after reaching a sufficient level of

3 saturation, which is the point at which no more insights were generated from the interviews (Strauss \&

4 Corbin 1990). We assured the respondents of confidentiality regarding the data that we collected from them.

5 We also utilized publicly available sources, including CSR reports, news reports and online government

6 publications such as the policies and laws that are relevant to the hospitality sector. These documents and

7 our observations served as the instruments for triangulation of the evidence (Miles and Huberman 1994).

\section{Insert Table 1 here}

We manually transcribed the interviews before subjecting the interview data and the data obtained from publicly available sources to thematic analysis. Drawing on Miles and Huberman (1994), we specifically looked for the similarities and differences in the transcribed data by subjecting them to open and axial coding. This was initially conducted by reading the data and tentatively assigning labels to specific items within them. We then iteratively reviewed the research questions and further identified two principal apriori themes from the literature review: internal organizational factors and institutional factors. These themes provided a basis for developing the primary list of codes. The primary list of codes included, for example, the external drivers of and barriers to sustainability for institutional factors. We subsequently drew categories within these codes to include the specific and third-level issues that are drawn from the theoretical underpinnings. For example, within the primary codes of external drivers, we created the following specific and third-level issues that were identified from the data: state regulation and local societal expectations. We iteratively reviewed the literature and transcripts several times by amending and supplementing the codes with previous iterations to inform and support the newer versions. The analytical process concluded with sense making and an interpretation of the data. 


\section{$1 \quad 4.0 \quad$ Findings}

\section{$2 \quad 4.1 \quad$ Drivers}

3 In this section, we examine the (internal and external) factors that positively influence the adoption of (parts

4 of) the sustainability agenda by the firms that operate in the hospitality industry in Malawi.

\subsubsection{Internal Drivers}

Top management/owners' commitment towards sustainability issues was a significant driver in the

8 adoption of sustainability agendas for all firms. The commitment of owners and managers was particularly

9 seen in the allocation of a firm's resources towards the implementation of sustainability initiatives. The

10 commitment of owner/managers and the degree of the adoption of the sustainability agenda varied across

11 the adopting firms. In general, locally owned and managed firms of all sizes were found to be strongly

12 committed to the implementation of charitable actions, although only a limited number of large firms

13 implemented initiatives that went beyond philanthropy.

17 These sentiments expressed by the owner/managers reflect the link between the personal values of the owner/managers and the nature of the sustainability agenda pursued. For the local owner/managers, their personal values, which closely match the Malawian cultural values of expecting the people who are 'well off' to offer assistance to the people who lack basic necessities, were invoked through their engagement in

21 philanthropy. In addition to putting their personal values into practice through such actions, their 22 engagement in philanthropic actions was rather symbolic and driven by the desire to enhance their image 
1 and achieve authority. In Malawian society, responding positively to societal expectations grants power to

2 the people who are considered to be charitable and generous, although the owner/managers may not

3 necessarily show a positive orientation towards other forms of the sustainability agenda. Similarly, we

4 observed that the few large locally owned hotels undertook a limited number of employee-focused and

5 environmentally related initiatives largely with the knowledge that the initiatives offered a strong business

6 case.

'Because Hotel Chain A values responsible waste management and encourages recycling through its CSR projects, the hotel chain immediately committed to donating all used paper from its 7 hotels and resorts as well as the corporate office to Tigwilizane Grouping.' (Excerpt from the Malawi Tourism Guide website²)

In contrast, we found that the owner/managers of many foreign-owned firms, irrespective of size, were committed to a broader sustainability agenda that encompassed other initiatives beyond philanthropy. The additional initiatives included environmental management, business integrity and employee welfare programmes.
'I think conducting business in this country comes with an obligation to help the society when need arises while not underestimating the importance of other sustainable business practices in achieving cost- efficiency.' (Owner of a medium-sized hotel)

Equally, for the owner/managers of these firms, their commitment towards a broad-based sustainability agenda may have been derived from their personal values and experience obtained from living, studying and working in western developed countries where sustainability is generally considered to be an issue that goes beyond philanthropy. However, it is important to note that within the foreign-owned and managed firms, the degree of the adoption of sustainability agendas varied depending on size. On the one hand, the majority of small firms showed a substantial adoption of the broad-based sustainability of all the dimensions

\footnotetext{
${ }^{2}$ See http://www.malawitourism.com/pages/news/index.asp?NewsID=557 (accessed $19^{\text {th }}$ October 2017).
} 
1 of sustainability (see Wickert et al. 2017). On the other hand, large and medium-sized firms were more

2 selective in the types of environmental initiatives and only considered the actions that were thought to be

3 associated with a strong business case. However, such a simplistic and unreflective view that engagement

4 in sustainability should be driven by a win-win situation may be counterproductive, especially when certain

5 sustainability practices that do not offer a strong business case are ignored (see Overall 2016; William et

6 al. 2017).

7 Cost saving considerations Our study finds that a number of firms considered cost savings to be one of the

8 reasons that they engaged in a sustainability agenda. This driver was considered to be important by foreign-

9 owned and managed large firms and SMEs that viewed the implementation of some environmental

10 management practices to be associated with some cost savings. The owner/managers of such firms

11 expressed the view that their firms were able to selectively adopt sustainable practices based on a thorough

12 assessment of the scale of investment and the benefits that such initiatives could offer in the long term.

'Implementing some of the environmental conservation practices can mean that we put in a lot of money. perpetual ESCOM power-outage problems, I think we can endure the financial pain now and reap the benefits later.' (Owner/manager of a medium-sized lodge)

17 Although cost saving considerations were largely seen by most of the foreign-owned firms to be a driver of 18 their engagement in an environmentally focused sustainability agenda, it is important to note that this driver 19 was not seen to be relevant to the environmental orientation of the local owner/managers of firms of all 20 sizes. A lack of knowledge about the business case for engaging in an environmentally focused 21 sustainability agenda may have limited their adoption of this type of sustainability agenda (see Mzembe et 22 al, 2016). For the locally owned and managed firms - especially the large and medium-sized firms - cost 23 saving considerations were largely considered in firms' adoption of a sustainability agenda that focused on 24 business integrity and anti-fraud. 
'My company subscribes to the national integrity programmes promoted by the government because we don't want in [the] future to be exposed to risks of corruption, bribery and fraud. (----) We train our staff in ethical issues and have employed an ethics officer to oversee this - we know it's a costly undertaking, but in my opinion, it can prevent loss of revenue'. (Manager of a large local hotel)

The significance that these owner/managers attach to business integrity and anti-corruption measures suggests the scale of their vulnerability to the loss of revenue and business because of corruption and fraud practices. Engaging in a collective fight against these anti-business integrity practices can lead not only to a reduction in the costs of litigation but also to the minimization of the costs associated with a loss of business dealings.

Parent Company Influences We found that pressure from the parent company was one of the significant drivers of the adopted sustainability agenda in the Malawian hospitality industry. Several multinational chains (MNCs) of hotels operate in Malawi through their subsidiaries in the form of management contracts with local owners of real estate such as the government of Malawi or a local company. Under this arrangement, the subsidiaries of the MNCs manage the hotels on behalf of the owners and are responsible for core business and operational strategies that to some extent mirror the strategies of their parent company. In relation to the adoption of the sustainability agenda in Malawi, we came across evidence of Malawian subsidiaries that strive to adopt and embed some of the parent company's sustainability policies and practices. The influence of parent companies on their subsidiaries' sustainability orientation is captured in the excerpt below from the CSR report for the year 2015/2016 of one of the multinational chains with operations in Malawi and across Southern Africa. the communities in which our resorts operate'. (Group Corporate Affairs and CSI Executive) 
1 Since Malawian subsidiaries are heavily reliant on their parent companies for their continued

2 existence, compliance with some of the parent company's policies and practices may be regarded as a

3 mechanism by which they can achieve the internal legitimacy of their operations and continued access

4 to (parent company) resources. However, the extent to which the parent company can influence the

5 sustainability agenda of their Malawian subsidiaries is conditioned on how the subsidiaries can

6 negotiate the local norms and values. We turn to this issue in the succeeding sections.

\section{$8 \quad$ 4.1.2 External Drivers}

9 State regulation The extant literature has highlighted the coercive influence of government regulations in 10 the uptake of sustainability agendas in the hospitality and tourism industry (Ayuso 2006; Rivera 2004; Tang

11 et al. 2014). Our study found that few industry-specific regulations promote the adoption of the 12 sustainability agenda amongst firms in Malawi. Most of these standards focus on the health and safety of 13 consumers and workers. Apart from such regulations, firms are also required to comply with a wide range of generic economic, social and environmental governance regulations.

Although having such a wide range of regulatory frameworks can be viewed as a positive and conducive environment for institutionalizing sustainable business practices, anecdotal evidence suggests

17 that compliance with such regulations within the industry is somewhat uneven (Times Group 2016 ${ }^{3}$ ). Small, 18 medium-sized and large firms with foreign owner/managers, as well as the majority of large locally owned 19 and managed firms, showed much more pro-activeness in complying with social and environmental 20 regulations. In contrast, the majority of small and medium-sized firms that are owned or managed by local 21 individuals exhibited a less positive stance towards such regulations. The situation in the Malawian industry 22 can be attributed to the inadequate enforcement of regulations largely because of limited institutional 23 capacities (Magombo 2011). The sentiments below, from one of the employees of a locally owned

\footnotetext{
${ }^{3}$ See http://www.times.mw/tourism-body-seals-32-hospitality-units/.
} 
1 restaurant, confirm the non-effectiveness of regulatory instruments in forcing firms to engage in sustainable

2 practices:

'Food safety in our restaurant is not a priority. (....). There have been numerous times when we have had no electricity for a long period, but we still served food which was on the verge of going bad. Nobody cares for the customers - even the City Council does not inspect our restaurants anymore'. (Employee of a locally owned, small restaurant)

It is apparent that such a regulatory vacuum leaves non-compliant businesses unpunished and can breed a view within compliant owner/managers that complying with the regulatory framework does not necessarily offer a strong business case. In addition, a lack of government capacity in terms of financial and human resources to monitor compliance means that regulatory oversight may be less on the local small and medium-sized firms that are less visible but heavily intensified for the large local firms and foreign-owned and managed firms of all sizes.

Societal norms and expectations Societal expectations regarding the role of business in societal issues was considered to be an important driver of the sustainability agenda of firms in the Malawian hospitality industry (see Melissen, Mzembe, Idemudia \& Novakovic, 2018; Mzembe \& Meaton 2014). The owner/managers of SMEs and large firms, regardless of the country of origin, expressed the view that they implemented sustainable practices, in particular the practices that are philanthropic in nature, as a direct response to the host communities' expectations regarding firms' contribution towards societal wellbeing. The quote below from one of the community respondents further illustrates and confirms not only the societal pressure on firms but also their response to such pressures:

'Last season, we lost shelter, livestock and crops because of drought and flooding. (----). We all expected lodges and hotels that are operating in this area to help. Luckily, these hotels and lodges donated blankets, seeds and other sanitary goods to us'. (Local community leader) 
1 However, it is fundamental to point out that the degree of commitment to meet such societal expectations

2 differed across firms. On the one hand, locally owned firms, regardless of size, tended to show a strong

3 commitment towards the philanthropic actions that are significantly favoured by Malawian society and

4 reflected the firms' strong embeddedness within Malawian society and owner/managers' increased

5 understanding of what their society needs and expects. Demonstrating a strong commitment towards

6 addressing societal challenges can provide such owner/managers some authority within their society.

'Donating to social causes is good here if you are a business person because that makes you being the focus of attention in the area. You command so much respect from the community. The local leaders here have worked very hard to act as an advisor to their development committees, but I think that would be going beyond my remit if I accept those ceremonial roles.' (Local owner of a restaurant and rest house)

Conversely, the locally owned and managed firms that do not show interest and commitment towards pressing societal issues are less regarded within their host communities and often face hostilities.

Another striking finding is with respect to the adoption of the sustainability agenda by the subsidiaries of the multinational chains of hotels. As stated elsewhere, we found that the agendas of Malawian based subsidiaries mirror to some extent the agendas of the parent company. However, these subsidiaries are also striving to align with the local societal expectations that favour philanthropically focused agendas as the sentiments below show:

'We are only concerned about being on good terms with the government inspectors (--------) and communities. We know that our colleagues in South Africa are implementing environmental management practices within the hotel facilities on a much larger scale because it is a must there. (---) Why would we retrofit our water system, for example, when we know that this investment won't bring us more money now? Our customers may not even take such improvements seriously after all. I think sponsoring community environmental projects is sufficient.' (Employee of a large foreign-managed hotel) 
1 For these subsidiaries, balancing local expectations and the expectations of their parent companies indicates

2 their quest to achieve both the internal and external legitimacy of their operations. However, striking a

3 balance between local expectations and the demands of their parent companies abroad means that the parent

4 companies' global or corporate sustainability agendas may be diluted. The compromise that is achieved in

5 determining a subsidiary's sustainability agenda suggests that there is a limit to the extent to which parent

6 companies can adapt and implement their sustainability agenda in their subsidiaries that are based in foreign

7 countries that have different values and norms (Husted \& Allen 2006; Jamali \& Neville 2011; Jamali, 2010;

8 Muthuri \& Gilbert 2011; Vashchenko 2017).

\subsubsection{Barriers}

11 In this section, we particularly examine the internal barriers that appear to hinder the hospitality firms in

12 Malawi in embracing a sustainability agenda. It must be pointed out that we found no evidence of external 13 barriers in the Malawian context.

\subsubsection{Internal Barriers}

Lack of knowledge about sustainability issues A significant proportion of the respondents, mostly the local

17 owner/managers of local firms regardless of the size of their firms, felt that a lack of knowledge about sustainability issues was one of the barriers to their engagement with a sustainability agenda. They particularly identified a lack of knowledge about environmental practices and how these practices could be integrated into their business operations as a major limitation to the implementation of a broad-based sustainability agenda. This is further compounded by the fact that most of these firms tend to have a low-

22 level education and a limited network of peers with information and knowledge on sustainability issues.

23 For example, one of the local owners of a hospitality firm stated that 
'I would have loved if there was more information about these issues that was widely available. The only way I can contribute to this at the moment is to make donations to charitable causes. I am ready to try out other actions should someone provide information about these things, but it would be good if the information was provided in a simplified form.' (Local owner of a medium-sized lodge)

5 This response further shows that for some of the local owner/managers, if information was available, it 6 would need to be presented in the most accessible way and tailored to their level of education and their 7 resource capacities to help enhance their adoption of a broad-based sustainability agenda.

Apart from a lack of knowledge about a broad-based sustainability agenda, it seems that many local owner/managers still do not have an adequate understanding of the economic or financial benefits of certain aspects of a sustainability agenda. In fact, many of them viewed the adoption and implementation of sustainable business practices as a significant cost burden: may be good for the society, but what is the benefit to my business?'

If owner/managers had information about specific sustainability initiatives and the cost implications of undertaking such initiatives, then they might be more motivated to conduct a cost-benefit analysis of each initiative for their adoption. Thus, ignorance about the long-term cost savings and social license to operate

17 benefits that may accrue from pursuing environmental sustainability hinders locally owned and managed firms in embedding environmental initiatives within their operations.

For their western counterparts, the knowledge and information about broad-based sustainability and

21 industry publications from abroad or through their home country experiences. 
on sustainability from former colleagues which I think has been quite valuable.' (Foreign owner of a medium-sized lodge)

This finding confirms the fact that owner/managers can draw on the values from their origin and links to the countries where a sustainability agenda is at an advanced stage, and they can use such links to frame a sustainability agenda in their firms abroad (see Mzembe et al. 2016).

7 Lack of resources The availability of resources in terms of finances, human resources and time was cited as a major factor for the firms that do not currently implement a sustainability agenda. It was also a factor for the firms that are currently implementing some form of sustainability actions. For small and mediumsized firms, regardless of the origin of their owner/managers, a lack of resources to invest in technical knowhow, equipment and human resources discouraged them from implementing the sustainability initiatives that particularly address environmental concerns. and have been retrofitting their buildings with new technologies to reduce energy and water bills. These businesses are run by rich South African investors - they can afford that. We can't afford this. I would be interested in trying out some of the technologies, but we are a very small family-owned business. (-----). Another problem for me is that apart from owning this busy restaurant, I also work for the government, and finding time to go and learn these issues has always been problematic'. (Local owner of a small restaurant and rest house)

The owner/managers such as the one quoted above consider the adoption of sustainable technologies to be

21 expensive, which could require a significant investment. The problem of a lack of resources for

22 sustainability was not only limited to the non-adopting firms. A lack of resources restricted the room for

23 continuous improvement for the firms that are already implementing some broad-based sustainable business

24 practices. In addition to a lack of financial resources, finding the time to learn, experiment with and 
1 implement time-consuming environmental management practices can equally be a challenge for small

2 businesses since running a hospitality business may not be their only economic activity. Many local

3 entrepreneurs typically run more than one business to have a secure flow of income. Time constraints can

4 be problematic to the adoption of a broad-based sustainability agenda, especially when the potential

5 sustainability initiatives offer limited benefits (Tzschenke et al. 2004).

\section{$7 \quad 5.0 \quad$ Discussion}

8 In general, our findings suggest that the firms with foreign ownership and management, irrespective of size,

9 undertook sustainability initiatives that were oftentimes philanthropic in nature but with limited orientation

10 towards the global sustainability agenda that offers a strong business case. Meanwhile, the locally owned

11 and managed small and medium-sized firms pursued philanthropically focused sustainability actions that

12 are deeply rooted in community values and expectations. We provide three explanations as to why this

13 might be the case in the Malawian hospitality industry that reveal the significance of the dynamics within

14 and between the individual drivers of and barriers to the adoption of sustainability agendas.

First, the variations in the agendas that were adopted by these firms reflect the influence of both societal expectations and the personal values and commitment of the owner/managers. Previous studies

17 have highlighted the significance of the commitment of the owner/managers to sustainability agendas in 18 the hospitality industry and have all underlined the influence of personal values, life experiences and 19 aspirations on a firm's sustainability orientation (Chassé \& Courrent 2018; Tinnish \& Lynch 2016;

20 Tzschenke et al. 2004; Williams et al. 2017). For the locally managed and owned small and medium-sized

21 firms, the more philanthropically based sustainability agenda was in response to Malawian societal 22 expectations that business should play a role in basic social rights provision. Furthermore, by virtue of their 23 embeddedness within local society, engaging in a more philanthropically focused agenda to address societal 24 challenges was considered to be the only way that the owner/managers could invoke their personal values 
1 of communitarianism and benevolence (Jamali \& Neville 2011). This argument contradicts Samara et al.'s

2 (2018) findings in their study of the influence of emotional and reputation attachment to family businesses

3 on sustainability agendas. Samara et al. (2018) suggest that in situations where the management of family

4 firms constitutes a mix of family members and external employees, the possibility of such a firm to access

5 broad-based knowledge about sustainability can be quite high. Thus, external members can bring in new

6 ways of doing things. In our study, small firms are often family-owned and managed and do not usually

7 have external boards of directors. As such, the injection of external ideas such as environmental

8 management practices to supplement the philanthropically focused sustainability practices is often limited.

9 Samara et al. (2018) have argued that in situations where the family-owned businesses are largely managed

10 by family members, having external directors with vast knowledge and experiences can lead to the

11 broadening of their sustainability agenda.

For the owner/managers of the foreign firms, irrespective of size, societal expectations presented a tension between their personal values and experiences that were developed throughout their life in their country of origin and the communitarian values that are espoused within their host societies (William et al. 2017). However, the adoption of a philanthropically focused sustainability agenda, although incorporating some environmental practices, underscores their orientation towards the values of enlightened self-interest

17 (Jansson, Nilsson, Modig \& Hed Vall 2017; Tinnish \& Lynch 2016; Tzschenke et al. 2004). Therefore, the owner/managers of such firms strove to pursue philanthropic actions to achieve societal legitimacy whilst simultaneously implementing environmental management practices that save costs. drivers, societal expectations and parent company influences, played a significant role in the adoption of a

22 sustainability agenda. However, these interactions were fraught with tensions. Convergence theory

23 stipulates that under ideal conditions, the global norms and values espoused by the parent companies might

24 diffuse into the host countries where subsidiaries are located (Jamali \& Neville 2011). However, in the

25 Malawian context, the subsidiaries adopted diluted forms of sustainability that to a large degree reflected

26 the coercive influences of local values and norms (Arenas \& Ayuso 2016; Ozdora-Aksak \& Atakan-Duman 
1 2016). However, it is important to note that to a small extent, the subsidiaries mimetically adopted some 2 actions from the parent companies' agendas to achieve internal legitimacy (Kostova \& Roth 2002). Third, internal organizational factors such as access to financial, human and technical resources by

4 firms can either serve as a driver of or a barrier to the adoption of particular sustainability agendas by firms

5 (Brammer et al. 2012). We found variations in the access to resources that corresponded to the different 6 countries of origin of the owner/managers, with Malawian owner managers having less access. These 7 differences had implications for the nature of the sustainability agendas adopted by various firms. In 8 general, a lack of slack resources and knowledge about environmental initiatives hampered the adoption of 9 broad-based sustainability agendas by the small and medium-sized firms that were locally owned and managed. Consequently, such firms found it more compelling to undertake philanthropically focused sustainability initiatives that were easy to implement and initiatives that demonstrated their commitment to their communitarian values and norms. This result is in line with the findings from previous studies

13 (Melissen et al. 2018; Mzembe \& Meaton 2014). For these firms, allocating scarce resources to environmental sustainability actions is not a priority if the business case for pursuing broad-based sustainability agendas is difficult to establish (Ayuso 2006). In contrast, the firms of all sizes that were foreign-owned and managed showed a favourable, albeit marginal, orientation towards a broad-based 17 sustainability agenda because they can access the required resources and knowledge (Best \& Thapa 2013). However, Baumann-Pauly et al. (2013) also found that for foreign-owned firms, the implementation of broad-based sustainability was similarly not affected by a lack of resources, although consideration should be given to contextual variations. Nevertheless, the differences in resource endowments and access to 21 sustainability knowledge can make it difficult to achieve uniformity in the adoption of sustainability 22 agendas across firms.

24 field in the Malawian context did not create as significant impacts on the adoption of sustainability agendas 25 in the hospitality industry as they create in other industries (see Mzembe \& Meaton 2014). In fact, at times, 26 there was a general understanding that these forces may have been counterproductive to firms' orientation 
1 towards sustainability. We found that robust laws for promoting broad-based sustainability agendas exist,

2 but their effectiveness was seriously hampered by limited state capacity. The enforcement of such laws was

3 sporadic and often targeted to only the firms that have a high visibility including not only large locally

4 owned firms but also foreign-owned and managed firms. Consequently, the compliance with regulations

5 was primarily reactive, and most locally owned and managed firms considered sustainability-related

6 regulations as threats to their business rather than as an opportunity to contribute to their economic interests

7 and the welfare of society (William et al. 2017). Sporadic regulatory enforcement, in situations where

8 owner/managers do not have ethical values, can disincentivize the compliant firms and simultaneously

9 solidify the spirit of non-compliance in the firms that might not already be compliant (Vives 2006).

\section{$11 \quad 6.0 \quad$ Conclusion}

12 This paper makes three important empirical contributions. First, in responding to a call for more empirical

13 studies that consider an integrative perspective, an approach that has been encouraged in recent studies

14 (Frynas \& Yamahaki 2016; Mallahi et al. 2016), this paper contributes to a wider on-going discussion about

15 the drivers of and barriers to the adoption of a sustainability agenda (Ayuso 2006; Brammer et al. 2012;

16 Frynas \& Yamahaki 2016; Jamali \& Karam 2018). We use a theoretical framework (Figure 1) that integrates

17 internal organizational factors, isomorphic factors in the organizational field and the nature of the firm (one

18 of the key elements of NBS). This framework facilitates an investigation of the individual and combined

19 influences of internal organizational and institutional factors on a sustainability agenda and of the dynamics

20 of and tensions in their relationship. In this way, this paper extends and builds on the debates about the

21 factors that are implicated in the adoption of sustainability. This paper further highlights the tensions that

22 exist for small and medium-sized businesses that are owned and managed by foreign individuals when their

23 personal values and commitment collide with local societal expectations (Seny Kan, Apitsa \& Adegbite.

24 2015). For such actors, societal expectations that favour a strong orientation towards philanthropically

25 focused sustainability actions conflict with their personal values and philosophies that are more with broad- 
1 based sustainability agendas. This finding suggests that the tensions between the different factors that are

2 involved in the adoption of a sustainability agenda should be considered in terms of global versus local

3 norms and values (Jamali \& Neville 2011; Kostova \& Roth 2002; Matten \& Moon 2008) and should also

4 consider the tensions between internal organizational factors and the isomorphic forces within the 5 organizational fields.

The second contribution that proceeds from the premise of our first contribution fills a gap in the

7 literature on the drivers of and barriers to a sustainability agenda in the hospitality industry in developing

8 countries. This paper extends our understanding of the formal and informal institutions in the adoption of

9 a sustainability agenda by suggesting that in this context, formal organizations can be counterproductive to

10 the institutionalization of sustainability agendas. Although previous studies make suggestions that formal

11 institutions such as the government, NGOs, trade and industry organizations can play a significant role in

12 the uptake of sustainable practices (Brammer et al. 2012; Kostova \& Roth 2002; Matten \& Moon 2008),

13 this paper shows that formal organizations such as the government and NGOs can have a limited impact on

14 the adoption of sustainability practices. This limitation leaves the pressure for sustainability to originate

15 from internal organizational factors and informal institutions in the form of local norms and values. In the

16 worst circumstances, ineffective formal institutions, such as government regulations, were seen to be

17 associated with the unintended negative impacts that may have engendered a spirit of non-compliance

18 amongst the firms that were less visible.

Third, this paper adds an African voice to the sustainability debates. Although the concept of voice in research is a contested term, it has been useful to hear how the dynamics of internal and external factors

21 play out in the organizational lives of the owners and managers in the hospitality sector of an African

22 country. Their accounts animate the theoretical perspectives and add empirical weight to the developed

23 theoretical model. Accordingly, this paper contributes to understanding business' role in society by focusing

24 on the complex dynamics of the adoption of sustainability agendas in an under-researched context. This

25 paper demonstrates how the tensions between internal organizational factors and local societal expectations

26 within host countries can shape the nature and focus of the sustainability agenda itself. 


\section{$1 \quad 7.0 \quad$ Implications for Managerial Practice and Public Policy}

2 Our paper has a number of implications for practice. First, managers who are implementing or planning to 3 implement a sustainability agenda in the Malawian hospitality industry (or in other developing countries)

4 should consider the influence of local institutional factors such as societal norms and expectations. This 5 consideration may be vital in enhancing the success of their agendas and may also help them to avoid a 6 misallocation of resources (Amaeshi et al. 2016b). However, responding to local expectations does not 7 necessarily mean abandoning the sustainability practices that may not be demanded by host societies.

8 Furthermore, we recommend that sustainability agendas should be strategically embedded within the firm 9 and not be seen only as an act of benevolence.

With respect to the public policy implications, our paper suggests that although the firms engaged

11 in some philanthropic actions to achieve a legitimization of their operations at the micro-level of Malawian 12 society, the legitimization of their operations in relation to their compliance with state regulations was somewhat limited. As revealed in this paper, this situation is compounded by the fact that the state acutely lacks the resources to enforce economic, social and environmental regulations. We therefore suggest that to ensure compliance with regulations, the state may need to provide some incentives to the firms that can mainstream social and environmental considerations in their operations (Midttun 2008). By virtue of being

17 the largest buyer of services and products that the industry offers, the state can lead by example through the 18 promotion of sustainability in its procurement practices by preferentially awarding contracts to 19 sustainability-oriented firms, for example. Such an intervention could highlight the business case to engage 20 in sustainability issues. The other area of state intervention may be to provide the necessary knowledge in 21 sustainability issues and facilitate access to the financial products that can help firms to develop the requisite 22 capabilities to develop sustainable business practices (Dentchev et al. 2015). To support this strategy, the 23 state can build the capacity of the industry associations to promote sustainability amongst its membership.

24 These industry bodies could play a fundamental role not only in sharing knowledge but also in showcasing 25 the best practices in sustainability. 


\section{$1 \quad$ 8.0 Limitations and Areas for Further Research}

2 This paper reveals the importance of focusing on the dynamics of various internal and external factors on

3 the adoption of sustainability agendas, but further studies could quantitatively evaluate the degree of

4 interactions to build on our qualitative mapping of the current situation. Moreover, our study adopted

5 purposive sampling of the respondents and was undertaken in a single country context. Further studies

6 could replicate our study in other developing countries to highlight the similarities, complementarities and

7 cross-national variations. Finally, given that sustainability or CSR agendas are relatively new concepts in

8 the Malawian hospitality industry, we suggest that further studies should be conducted in Malawi and

9 elsewhere to investigate the influence of culture and a colonial legacy on the dominant understanding of 10 sustainability.

\section{References}

Abdalla, Y.A. \& Siti-Nabiha, A.K. (2015). Pressures for sustainability practices in an oil and gas company: Evidence from Sudan. Qualitative Research in Accounting \& Management, 12(3), 256 - 286.

Ali, W., Frynas, J. G. \& Mahmood, Z. (2017) Determinants of Corporate Social Responsibility (CSR) disclosure in developed and developing countries: a literature review. Corporate Social Responsibility and the Environmental Management., 24: 273-294.

Amaeshi, K., Adegbite, E., Ogbechie, C., Idemudia, U., Seny Kan, K.A., Mabumba, I.\& Obianuju, A.I.J. (2016a). Corporate social responsibility in SMEs: a shift from philanthropy to institutional works? Journal of Business Ethics, 138(2), $385-400$.

Amaeshi, K., Adegbite, E. \& Rajwani. T. (2016b). Corporate social responsibility in challenging and nonenabling institutional contexts: do institutional voids matter? Journal of Business Ethics, 134(1), 135153.

Aragón Amonarriz, C. \& Iturrioz Landart, C. (2016). 'Responsible family ownership in small- and mediumsized family enterprises: an exploratory study. Business Ethics: A European Review, 25: 75-93.

Arenas, D. \& Ayuso, S. (2016). Unpacking transnational corporate responsibility: coordination mechanisms and orientations. Business Ethics: A European Review, 25: 217-237.

Ayuso, S. (2006). Adoption of voluntary environmental tools for sustainable tourism: analyzing the experience of Spanish hotels. Corporate Social Responsibility and Environmental Management, 13: 207-220. 
Baumann-Pauly, D., Wickert, C. \& Spence, L.J. (2013). Organizing corporate social responsibility in small and large firms: size matters. Journal of Business Ethics, 115 (4), 693 - 705.

Bello, F.G., Banda, W.J.M. \& Kamanga, G. (2017). Corporate Social Responsibility (CSR) practices in the hospitality industry in Malawi. African Journal of Hospitality, Tourism and Leisure, 6 (3), 1 - 21.

Benito-Hernández, S., Platero-Jaime, M. \& Esteban-Sánchez, P. (2016). The influence of cooperative relations of small businesses on environmental protection intensity. Business Ethics: A European Review, 25: 416-439.

Best, M.N. \& Thapa, B. (2013). Motives, facilitators and constraints of environmental management in the Caribbean accommodations sector. Journal of Cleaner Production, 52: 165-175.

Blundel, R., Monaghan, A. \& Thomas, C. (2013). SMEs and environmental responsibility: a policy perspective. Business Ethics: A European Review, 22: 246-262.

Brammer, S., Hoejmose, S. \& Marchant, K. (2012). Environmental management in SMEs in the UK: practices, pressures and perceived benefits. Business Strategy and the Environment, 21: 423-434.

Chan, E.S.W. (2008). Barriers to EMS in the hotel industry. International Journal of Hospitality Management, 27: 187-196.

Chassé, S. \& Courrent J-M. (2018). Linking owner-managers' personal sustainability behaviors and corporate practices in SMEs: the moderating roles of perceived advantages and environmental hostility. Business Ethics: A European Review, 27:127-143.

Charbel, S., Ellie, B. \& Samara, G. (2013). Impact of family involvement in ownership management and direction on financial performance of the Lebanese firms. International Strategic Management Review, 1(1): $30-41$.

Craig J. \& Dibrell C. (2006). The natural environment, innovation, and firm performance: a comparative study. Family Business Review, 19: 275-288.

Dentchev, N. A., van Balen, M. \& Haezendonck, E. (2015). On voluntarism and the role of governments in CSR: towards a contingency approach. Business Ethics: A European Review, 24: 378-397.

DiMaggio, P. \& Powell, W. (1983). The iron cage revisited: institutional isomorphism and collective rationality in organizational fields. American Sociological Review, 48(2), 147 - 160.

Dodds, R.\& Holmes, M. R. (2011). Sustainability in Canadian B\&Bs: comparing the east versus west. International Journal of Tourism Research, 13: 482-495.

Doluca, H., Wagner, M. \& Block, J. (2017). Sustainability and environmental behavior in family firms: A longitudinal analysis of environment -related activities, innovation and performance. Business Strategy and the Environment, 27(1): 152-172.

Eweje, G. (2011). A shift in corporate practice? Facilitating sustainability strategy in companies. Corporate Social Responsibility and Environmental Management, 18: 125-136. 
Forcadell, F.J. \& Aracil, E. (2017). Sustainable banking in Latin American developing countries: leading to (mutual) prosperity. Business Ethics: A European Review, 26:382-395.

Frynas, J. G. \& Yamahaki, C. (2016). Corporate social responsibility: review and roadmap of theoretical perspectives. Business Ethics: A European Review, 25: 258-285.

Government of Malawi (2006). National tourism policy. Lilongwe: Malawi Government Press.

Graafland, J. \& Smid, H. (2016). Environmental impacts of SMEs and the effects of formal management tools: evidence from EU's largest survey. Corporate Social Responsibility and Environment Management, 23: 297-307.

Gregory-Smith, D., Manika, D. \& Demirel, P. (2017). Green intentions under the blue flag: exploring differences in EU consumers' willingness to pay more for environmentally-friendly products. Business Ethics: A European Review, 26:205-222.

Hofman, P.S., Moon, J. \& Wu, B. (2017). Corporate social responsibility under authoritarian capitalism: dynamics and prospects of state-led and society-driven CSR. Business \& Society,56(1): 651 - 671.

Husted, B.W. \& Allen, D.B. (2006). Corporate social responsibility in the multinational enterprise: strategic and institutional approaches. Journal of International Business Studies, 37: 838 - 849.

Hyatt, D. G., \& Berente, N. (2017). Substantive or symbolic environmental strategies? Effects of external and internal normative stakeholder pressures. Business Strategy and the Environment, 26: 1212-1234.

Jain, T. \& Jamali, D. (2016). Looking inside the Black Box: the effect of corporate governance on corporate social responsibility. Corporate Governance: An International Review, 24(3), 253 - 273.

Jamali, D. (2010). The CSR of MNC subsidiaries in developing countries: Global, local, substantive or diluted? Journal of Business Ethics, 93: 181-200.

Jamali, D., Karam, C., Yin, J., \& Soundararajan, V. (2017). CSR logics in developing countries: Translation, adaptation and stalled development. Journal of World Business, 52(3), 343-359.

Jamali, D. \& Karam, C. (2018). Corporate social responsibility in developing countries as an emerging field of study. International Journal of Management Reviews, 20: 32 - 61.

Jamali, D. \& Neville, B. (2011). Convergence versus divergence of CSR in developing countries: an embedded multi-layered institutional lens'. Journal of Business Ethics, 102: 599 - 621.

Jansson, J., Nilsson, J., Modig, F., \& Hed Vall, G. (2017) Commitment to sustainability in Small and Medium-Sized Enterprises: the influence of strategic orientations and management values. Business Strategy and the Environment, 26: 69-83.

Kostova, T. and Roth, K. (2002). Adoption of an organizational practice by subsidiaries of multinational corporations: institutional and relational effects. Academy of Management Journal, 45(1), 215-233. 
Kusi-Sarpong, S., Sarkis, J., \& Wang, X. (2016). Assessing green supply chain practices in the Ghanaian mining industry: a framework and evaluation. International Journal of Production Economics, 181: (Part B), $325-341$.

Lehnert, K., Craft, J., Singh, N., \& Park, Y. (2016). The human experience of ethics: a review of a decade of qualitative ethical decision - making research. Business Ethics: A European Review, 25(4), 498 537.

Lindgreen, A., Swaen, V., \& Campbell, T.T. (2009).Corporate social responsibility practices in developing and transitional countries: Botswana and Malawi. Journal of Business Ethics, 90( Supplement 3), 429-440.

Magombo, A. (2011). The development of tourism and the accommodation sector in Malawi since independence. Unpublished Thesis, University of Witwatersrand, Johannesburg, South Africa.

Matten, D. \& Moon, J. (2008). "Implicit" and "explicit" CSR: A conceptual framework for a comparative understanding of corporate social responsibility. The Academy of Management Review, 33: 404-424.

Melissen, F., Mzembe, A., Idemudia, U. \& Novakovic, Y. (2018) Institutional antecedents of the corporate social responsibility (CSR) narrative in the developing world context: Implications for sustainable development. Business strategy and the environment, 27(6), $657-676$.

Mellahi, K., Frynas, J.G., Sun, P., \& Siegel, D. (2016). A review of the nonmarket strategy literature: toward a multi-theoretical integration. Journal of Management, 42 (1), 143 - 173.

Mensah, I.(2006). Environmental management practices among hotels in the Greater Accra region. International Journal of Hospitality Management, 25(3), 414 - 431.

Meyer, J.W. \& Rowan, B. (1977). Institutionalized organizations: formal structure as myth and ceremony. America Journal of Sociology, 83(2), 340 - 363.

Midttun, A. (2008). Partnered governance: aligning corporate responsibility and public policy in the global economy. Corporate Governance: The international journal of business in society, 8(4), $406-$ 418.

Miles, M.B. \& Huberman A.M. (1994). Qualitative Data Analysis. Thousand Oaks: Sage Publications.

Muthuri, J.N. \& Gilbert, V. (2011). An institutional analysis of corporate social responsibility in Kenya. Journal of Business Ethics, 98(3), 467-483.

Mzembe, A.N., Downs, Y. and Meaton, J. (2016a). Corporate Social Responsibility in Malawi: Antecedents, Issues, Practices and Future Directions. In S. Vertigan, S. Idowu, \& R. Schmidpeter. (Eds.), Corporate Social Responsibility in Sub-Saharan Africa: Sustainable Development in its Embryonic Form: 3- 29. Heidelberg: Springer.

Mzembe A. N. \& Meaton J. (2014). Driving corporate social responsibility in the Malawian Mining Industry: a stakeholder perspective. Corporate Social Responsibility and Environmental Management, 21: 189-201.

Nsiku, N. \& Kiratu, S. (2009). Sustainable Development Impacts of Investment Incentives: A Case Study of Tourism Sector. Retrieved from 
https://www.iisd.org/sites/default/files/publications/sd_inv_impacts_malawi.pdf on 16th December 2016.

Ozdora-Aksak, E. \& Atakan-Duman, S. (2016). Gaining legitimacy through CSR: an analysis of Turkey's 30 largest corporations. Business Ethics: A European Review, 25: 238-257.

Overall, J. (2016). Unethical behavior in organizations: empirical findings that challenge CSR and egoism theory. Business Ethics: A European Review, 25: 113-127.

Peermont Casinos \& Resorts (2016) Corporate social investment and responsibility 2015/2016. Accessed on $15^{\text {th }}$ August 2016 at http://www.peermont.com/Assets/CSI\%20brochure\%202015-web-spreads.pdf

Pérez-López, D., Moreno-Romero, A.,\& Barkemeyer, R. (2015). Exploring the relationship between sustainability reporting and sustainability management practices. Business Strategy and the Environment, 24: 720-734

Perry, P. \& Ahmad, A. (2016). Islamic and Buddhist perspectives of corporate social responsibility. In A Örtenblad (ed.), Research Handbook on Corporate Social Responsibility In Context. Cheltenham: Edward Elgar, pp. 69-87.

Ramanathan, R., Poomkaew, B. \& Nath, P. (2014). The impact of organizational pressures on environmental performance of firms. Business Ethics: A European Review, 23: 169-182.

Revell, A.\& Blackburn, R. (2007). The business case for sustainability? An examination of small firms in the UK's construction and restaurant sectors. Business Strategy and the Environment, 16: 404-420.

Rivera, J. (2004). Institutional pressures and voluntary environmental Behavior in Developing Countries: evidence From the Costa Rican hotel industry. Society \& Natural Resources: An International Journal, 17(9), 779-797.

Rua, T., Lawter, L. \& Andreassi, J. (2017). Desire to be ethical or ability to self-control: which is more crucial for ethical behaviour? Business Ethics: A European Review, 26(3), 288 -299.

Russo, M.V. \& Fouts, P.A. (1997). A resource-based perspective on corporate environmental performance and profitability. Academy of Management Journal, 40(3), 534 - 559.

Sahasranamam, S. \& Ball, C. (2018). National context matters: Influence of national business system on social enterprises in Scotland and India. In L.J. Spence, J.G. Frynas, J. Muthuri \& J. Navare (eds.), Research handbook on Small Business Social responsibility: Global perspectives. Cheltenham: Edward Elgar, pp. 23-46.

Sajjad, A., Eweje, G. \& Tappin, D. (2015). Sustainable supply chain management: motivators and barriers. Business Strategy and the Environment, 24: 643-655.

Samara, G., Jamali, D., Sierra, V. \& Parada, M.J. (2018). Who are the best performers? The environmental social performance of family firms. Journal of Family Business Strategy, 9 (1), 33 - 43.

Scott, W.R. (2008). Institutions and organizations: ideas and interests. Thousand Oaks, CA: Sage

Seny Kan, K.A., Apitsa, S.A. \& Adegbite, E. (2015). African management: concept, content and usability. Society and Business Review, 10(3), 258 - 279. 
0

Soobaroyen, T. \& Ntim, C.G. (2013). Social and environmental accounting as symbolic and substantive means of legitimation: the case of HIV/AIDS reporting in South Africa. Accounting Forum, 37(3), 92 109.

Strauss, A. \& Corbin, J. (1990). Basics of Qualitative Research Grounded Theory Procedures and Techniques. Newbury Park, CA: Sage Publications.

Tang Y. H., Amran A. \& Goh Y. N. (2014). Environmental management practices of hotels in Malaysia: stakeholder perspective. International Journal of Tourism Research, 16( 6), 586-595.

Testa F., Gusmerottia, N.M., Corsini, F., Passetti, E. \& Iraldo, F. (2015). Factors affecting environmental management by small and micro firms: the importance of entrepreneurs' attitude and environmental investment. Corporate Social Responsibility and Environmental Management, 23: 373-385.

Tinnish, S.M. \& Lynch, K.D. (2016). The role of leadership and organizational competencies in corporate social responsibility programmes. In M.A. Gardetti, \& A.L. Torres (Eds.), Sustainability in Hospitality: How Innovative Hotels are transforming the Industry. 79 - 96. Sheffield: Greenleaf Publishing.

Tzschentke, N., Kirk, D. \& Lynch, P.A. (2004). Reasons for going green in serviced accommodation establishments. International Journal of Contemporary Hospitality Management, 16(2), 116 - 124.

Vashchenko M. (2017). An external perspective on CSR: what matters and what does not? Business Ethics: A European Review, 26:396-412.

Viveros, H. (2016). Examining stakeholders' perceptions of mining impacts and corporate social responsibility. Corporate Social Responsibility and Environmental Management, 23: 50-64.

Wickert, C., Vaccaro, A. \& Cornelissen, J. (2017). 'Buying'” corporate social responsibility: organisational identity orientation as a determinant of practice adoption. Journal of Business Ethics, 142 (3), 497. 514.

Williams, S., Schaefer, A. \& Blundel, R. (2017). Understanding value conflict to engage SMEs with business greening. In J.D. Rendtorff (Ed.), Perspectives on Philosophy of Management and Business Ethics. 73 -91. Dordrecht/Heidelberg/New York/London: Springer International AG.

Wood, G. \& Frynas, J.G. (2006). The institutional basis of economic failure: anatomy of the segmented business system. Socio-Economic Review, 4 (2), 239-277.

Yu, J., Lo, C. W.-H. and Li, P. H. Y. (2017). Organizational visibility, stakeholder environmental pressure and corporate environmental responsiveness in China. Business Strategy and the Environment, 26: 371384. 


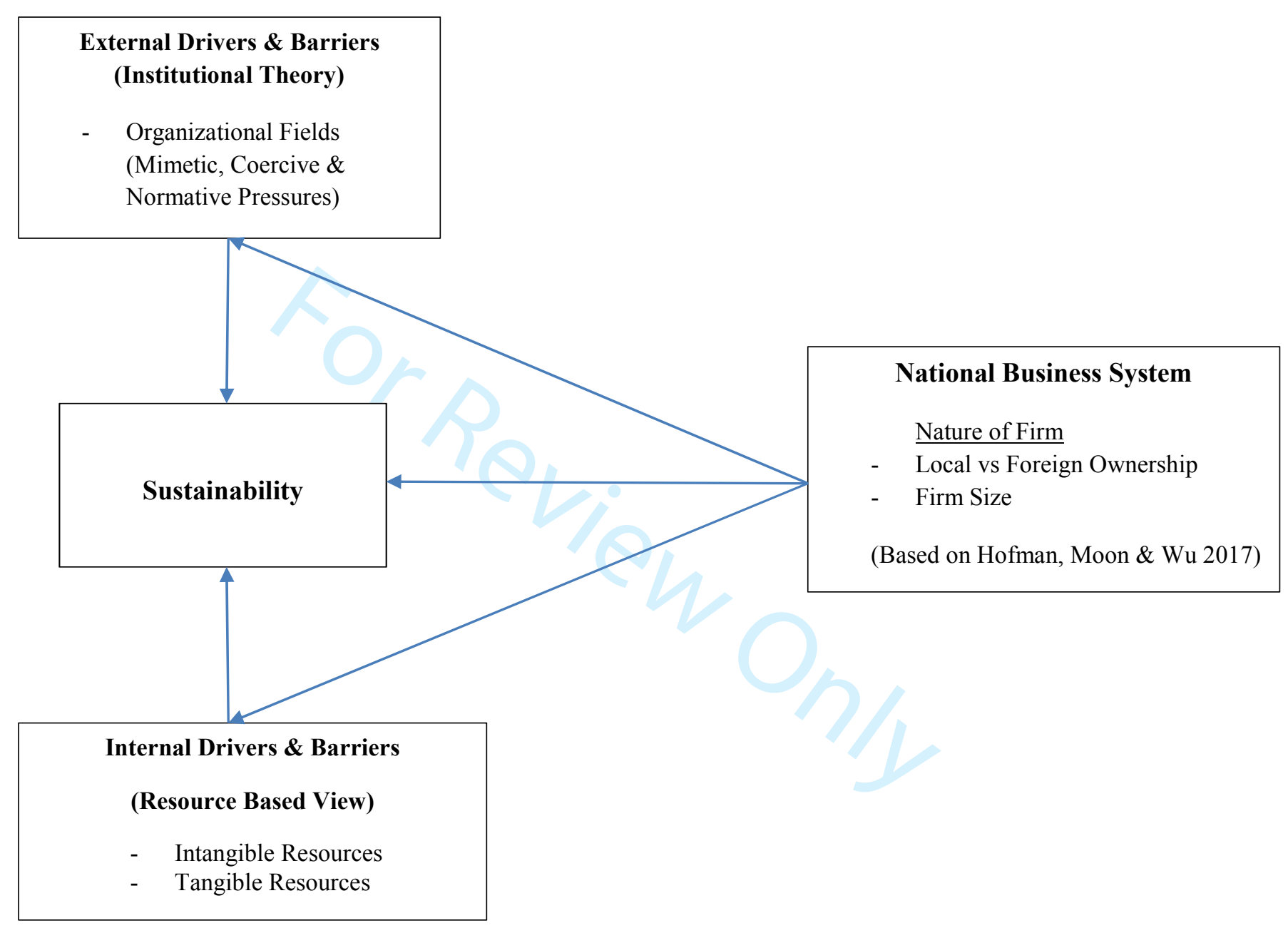

Figure 1 A Conceptual Framework for understanding the Drivers of and Barriers to Sustainability

Source: $\quad$ Based on Frynas and Yamahaki (2016) \& Hofman, Moon \& Wu (2017) 
Table 1 Descriptive information of Sampled Firms

\begin{tabular}{|c|c|c|c|c|c|c|}
\hline \multirow{2}{*}{$\begin{array}{l}\text { Firm } \\
\text { Number }\end{array}$} & \multicolumn{3}{|c|}{ Details of Respondents } & \multicolumn{3}{|l|}{ Details of the Firm } \\
\hline & Position & $\begin{array}{l}\text { Education } \\
\text { Level }\end{array}$ & Foreigner / Local & Nature of Operations & Size $^{1}$ & Ownership \\
\hline 1 & Manager & Tertiary & Local & Hotel & Large & Local \\
\hline 2 & Manager & Tertiary & Foreigner & Hotel & Large & Foreign \\
\hline 3 & Manager & Tertiary & Foreigner & Hotel & Large & Foreign \\
\hline 4 & Owner & Secondary & Local & Restaurant & Small & Local \\
\hline 5 & Owner & Secondary & Local & Restaurant & Small & Local \\
\hline 6 & Owner & Secondary & Local & Lodge & Medium & Local \\
\hline 7 & Manager & Tertiary & Foreigner & Hotel & Large & Foreign \\
\hline 8 & Manager & Tertiary & Local & Hotel & Large & Foreign \\
\hline 9 & Owner & Primary & Local & Restaurant & Small & Local \\
\hline 10 & Owner & Secondary & Local & Restaurant & Small & Local \\
\hline 11 & Owner & Secondary & Foreigner & Lodge & Medium & Foreign \\
\hline 12 & Owner & Secondary & Local & Lodge & Medium & Local \\
\hline 13 & Owner & Primary & Local & Restaurant & Small & Local \\
\hline 14 & Owner & Secondary & Local & Restaurant & Small & Local \\
\hline 15 & Owner & Secondary & Local & Lodge & Small & Local \\
\hline 16 & Owner & Primary & Local & Restaurant & Small & Local \\
\hline
\end{tabular}

${ }^{1}$ Size based on annual turnover and employee numbers as classified by the Government of Malawi (1998). Large firm has annual turnover of USD 232,558 (1 USD = MK43 at 1998 rate) and above, and employs 100 people or more; medium firm employs between 21 and 100 people, and has an annual turnover of between USD93,023 and USD 232,557. A typical small firm has employees 5 to 20 people, and can have an annual turnover of between USD2790 and USD93,022.

Figures have been sourced from http://www.moit.gov.mw/index.php/home/departments/private-sector-development/small-medium-enterprises 


\begin{tabular}{|l|l|l|l|l|l|l|}
\hline $\begin{array}{l}\text { Firm } \\
\text { Number }\end{array}$ & \multicolumn{2}{|l|}{ Details of Respondents } & \multicolumn{2}{l|}{ Details of the Firm } \\
\hline & Position & $\begin{array}{l}\text { Education } \\
\text { Level }\end{array}$ & Foreigner/Local & Nature of Operations & Size $^{\mathbf{1}}$ & Ownership \\
\hline 17 & Owner & Secondary & Local & Lodge & Medium & Local \\
\hline 18 & Manager & Secondary & Foreigner & Lodge & Medium & Foreign \\
\hline 19 & Owner & Secondary & Local & Lodge & Small & Local \\
\hline 20 & Owner & Primary & Local & Lodge & Small & Local \\
\hline 21 & Owner & Secondary & Local & Restaurant & Small & Local \\
\hline
\end{tabular}

